chiefly by the external electron configuration of the atom-the isotopic effect enters only as a part of a hyperfine structure of the individual multiplet lines.

On account of the increased attention now being given to the study of very rare isotopes (abundances less than 1 in 1000) we would like to suggest that, in investigations where the isotopes of neighbouring elements (present as impurities) might cause difficulty, the preparations should be submitted to a spectroscopic analysis before the results are considered as final. As is well known, the sensitivity of the spectroscopic method surpasses that of any chemical test.

$$
\begin{aligned}
& \text { H. SCHULER. } \\
& \text { E. GWynne Jones. } \\
& \text { Astrophysikalisches Observatorium, } \\
& \text { Einstein-Institut, Potsdam, } \\
& \text { May } 4 .
\end{aligned}
$$

1 H. Schüler and E. G. Jones, Naturwiss., 20, 171; 1932.

F. W. Aston, NATURE, 129, 649, April 30, 1932.

3 H. Schüler and J. E. Keyston, Z. Phys., 70, 1; 1931; confirmed by F. W. Aston, NATURE, 128, 725, Oct. $2 \frac{1}{x}, 1931$.

\section{Activated Adsorption of Hydrogen}

THE great revival of interest in adsorption measurements, carried out in connexion with catalytic experiments, which is manifested by the Oxford meeting of the Faraday Society, and by other similar publications, has prompted us to announce some results which we have obtained.

The adsorptions of hydrogen, hexane, cyclo-hexane, and benzene, at temperatures up to $450^{\circ}$, have been measured on a large number of metallic oxides. Attention has been primarily concentrated on substances which have known catalytic activities in hydrogenation, and on those which have not already been inspected by Prof. Taylor in Princeton. We have discovered that extensive 'activated' adsorption of hydrogen occurs with oxides of molybdenum, vanadium, chromium, and tungsten, and with metallic tin and cadmium.

Adsorption of hydrocarbons at high temperatures (up to $450^{\circ}$ ) is now found to be a still more general phenomenon, and takes place with every metal or metallic oxide which we have inspected so far $(\mathrm{Cr}$, $\mathrm{Ti}, \mathrm{Fe}, \mathrm{Cu}, \mathrm{Mo}, \mathrm{Zn}, \mathrm{Cd}, \mathrm{Ca}, \mathrm{Zr}, \mathrm{Mg}, \mathrm{Sn}, \mathrm{Co}, \mathrm{Al}, \mathrm{Mn}$, and $W$ ). The velocity and extent of the adsorption vary greatly in different cases, and are also considerably influenced by the presence of impurities; complications due to interaction of hydrogen with the solid have been avoided by pretreatment of the latter.

It is hoped to give an account, in extenso, of these experiments in the near future, as they should provide an interesting contribution to the study of catalysis.

\section{H. Holuings.}

R. H. Griffith.

Fulham Laboratory,

The Gas Light and Coke Co., London, May 12.

\section{Interaction of Flavones and Anthocyanins}

RobINSON and Robinson " have recently directed attention to the existence of 'co-pigments' which, entering into loose combination with anthocyanin pigments, modify their colour.

In the course of my genetic experiments on Dahlia variabilis, it was found that the ivory flavone in the flowers apparently had the property of changing the anthocyanin colour in the direction of blue; for example, cyanin alone gives almost a chocolate colour but with ivory flavone the colour is bluish-purple. Apparently ivory flavone acts as a co-pigment for cyanin and pelargonin in Dahlia.

No. 3266, VoL. 129]
Recently I have tested, inter alia, the crude pigment extracts from flowers of widely different plants (for example, Dahlia, Primula spp., Pelargonium, Tulipa, and Pulmonaria). In a number of cases the ivory flavone pigments, independent of hydrogen ion concentration, have been found to bring about modification of anthocyanin colour. The blueness disappears on heating the solution, but returns on cooling. The ivory flavone effect may be additional to that of co-pigments, other than flavone, already present. Reciprocal differences were found in certain cases.

Further, in Dahlia there is an inverse correlation between the production of flavones and anthocyanins, the interaction being reciprocal, but to the advantage of the flavones; thus if much flavone is produced, then little anthocyanin is formed. The same phenomenon occurs in other plants. Anthocyanin intensity, therefore, may depend to a considerable extent on the presence or absence of flavones.

Changes in the hydrogen ion concentration of the sap have long been known as one cause of flower colour variation. Differences in the specificity of the anthocyanins constitute another. In view of the universal distribution of flavones, it seems probable that they will be found to comprise an important and hitherto unrecognised source of variation in both flower colour and intensity. A full account of these experiments will be published elsewhere.

W. J. C. LAWRENCE.

John Innes Horticultural Institution,

Merton Park, London, S.W.19, April 30.

1 Robinson, G. M., and R. Robinson, Biochem. J., 25, 1687 ; 1931.

\section{Science and Disarmament}

AN article in NATURE of April 4, 1931, pointed out the connexion between science and the preparation for war, in reference to Major Lefebure's book, "Scientific Disarmament". I understand from friends of mine, who are scientific workers, that in all countries some men of science regard as important the problem of their own moral responsibility for the use of scientific knowledge in preparation for war. Deliberate application of science in the development of armaments is transforming the nature of weapons and the general character of war. As Major Lefebure has shown, the gravest problem is the development of new types of weapon; and yet neither the official policies of governments nor the proposals of unofficial bodies seem to envisage this problem.

Would it not be possible to form a small group of chemists, physicists, and other scientific workers of standing, in Great Britain-and also in France, Germany, and the United States-in order to make some public statement against the application of research to the improvement of gunnery, bombing, and chemical warfare? Such a statement would have influence in directing the minds of students of science towards their moral responsibility for the use of new knowledge; and the Disarmament Conference, now in session at Geneva, would be assisted if scientific workers, who provide the means for increasing the destructiveness of war, were to indicate publicly the gravity of the danger. It is obviously quite useless to abolish old armaments, if new and more deadly types of weapon are to be produced by the application of scientific research to such an end.

\section{Delisle Burns}

(Stevenson Lecturer in Citizenship):

University of Glasgow, May 16. 